\title{
Processos de apropriação da atividade de tradução e o controle da variação nos textos-alvo
}

\author{
Processes of appropriation of the translation activity and the control of variation \\ in target-texts
}

\author{
Elaine Aguiar Florêncio ${ }^{1}$ \\ Universidade do Estado de Mato Grosso \\ Albano Dalla Pria ${ }^{2}$ \\ Universidade do Estado de Mato Grosso
}

\begin{abstract}
- RESUMO: O estudo dos princípios que regulam a variação nos textos-alvo é o principal objetivo desse trabalho. Para tanto, assumimos a hipótese de Pria (2014) sobre a variação na superfície dos textos-alvo. O pesquisador argumenta que, antes de avaliar em termos da eficácia do trabalho do tradutor, os textos-alvo devem ser considerados em articulação com cada situação de enunciação e com cada processo particular de apropriação da linguagem. Nossa reflexão teve por base traduções do inglês para o português. Sustentados pelos fundamentos teóricos e metodológicos da Teoria das Operações Predicativas e Enunciativas (CULIOLI, 1990; 1999a; 1999b), construímos um sistema de representação metalinguística para dar visibilidade à atividade de tradução e para apreender os marcadores variáveis da ancoragem situacional exibidos nos textos-alvo.
\end{abstract}

- PALAVRAS-CHAVE: Operações Enunciativas. Tradução. Inglês. Português.

- ABSTRACT: The study of the principles that regulate the variation in targets-texts is the main objective of this paper. For that we assumed Pria's (2014) hypothesis on the surface variation of target-texts. He argues before to be evaluated the translator's work in terms of efficacy target-texts should be considered in articulation with each uttering situation and each language appropriation processes. Our reflection is based on translations from English to Portuguese. Theory of Predicative and Enunciative Operations (CULIOLI, 1990; 1999a; 1999b) assumptions supported the system of metalinguistic representation we constructed to give visibility to the translation activity and to apprehend variable markers of situational anchorage exhibited in target texts.

- KEYWORDS: Enunciative Operations. Translation. English. Portuguese.

\section{Introdução}

Uma coisa é certa, os mal-entendidos da tradução são tão velhos quanto o mundo das línguas e da linguagem. A Torre de Babel ilustra muito bem essa má compreensão. É um mito recorrente, nos trabalhos que teorizam a tradução, para ilustrar a incompreensão dos homens uns em relação aos outros em razão das muitas línguas faladas entre eles. Semelhante incompreensão também se observa entre os teóricos da

\footnotetext{
${ }^{1}$ Mestre em Linguística pelo Programa de Pós-Graduação em Linguística da UNEMAT/Cáceres. Doutoranda em Linguística pelo mesmo PPGL. Membro do grupo de pesquisa Variação e invariantes na linguagem. elaine_aguiar85@hotmail.com

${ }^{2}$ Pós-doutorado pela Universidade Nova de Lisboa (Bolsista CAPES - Proc. $n^{\circ}$ 99999.006159/2014-01). Doutor em Linguística e Língua Portuguesa pela UNESP/Araraquara. Docente do Curso de Letras da UNEMAT/Alto Araguaia e do Programa de Pós-graduação em Linguística da UNEMAT/Cáceres. Coordenador do Grupo de Pesquisa Variação e invariantes na linguagem. adallapria@gmail.com
} 
tradução sobre o que se entende por "tradução", por "tradutor" e por "texto". Nosso objetivo primeiro é contribuir para a fundamentação desses conceitos do ponto de vista da Teoria das Operações Predicativas e Enunciativas (CULIOLI, 1990).

Também é certo que traduzir do inglês para português as chamadas "construções resultativas", tais como John swept the house clean, John painted the house yellow, She laughed him out of his patience, John washed the soup out of his eyes, e assim por diante, não deixa de colocar alguma dificuldade aos tradutores, em especial, aprendizes em processo de apropriação da língua estrangeira. Bertucci (2014) chega a defender que na língua portuguesa não há expressões equivalentes, isto é, expressões que mantenham equivalência sintática com aquelas do inglês.

Fundamentado pelo posicionamento construtivista (FRANCKEL, 2011) da atividade de linguagem, nosso objetivo segundo, que visa dar sustentação ao objetivo primeiro, é muito mais explicitar os processos de apropriação que sustentam a atividade de tradução do que fomentar a polêmica sobre a existência das construções resultativas no português brasileiro. Há muitos trabalhos que, fundamentados pelo conceito de classe, assim o fazem. Por isso, não retomaremos essa polêmica, em particular. Optamos por fundamentar nossa reflexão pelo conceito de gesto assertivo (CULIOLI, 1990), que visa apreender o movimento da linguagem na passagem de um conteúdo de pensamento por vários planos de representação, quais sejam o plano das representações mentais, o plano das representações linguísticas e o plano das representações metalinguísticas (CULIOLI, 1990).

Para tanto, este trabalho parte de três hipóteses: primeiro, entendemos que a análise de fragmentos de língua pouco contribuí para se afirmar quais representações são possíveis numa dada língua; segundo, compreendemos que o domínio da tradução ainda carece de um conceito de tradução que leve em conta a articulação da linguagem com as línguas naturais; terceiro, em toda atividade de tradução, para chegar ao textoalvo os tradutores tiveram de localizar o texto-fonte em relação a uma situação particular de construção de significação.

Fundamentados pelos princípios da Teoria das Operações Predicativas e Enunciativas (doravante TOPE), principalmente a tese da indeterminação da linguagem e a definição de linguagem enquanto prática de construção de representação, de referenciação e de regulação (CULIOLI, 1990), esperamos contribuir para uma teoria da atividade de tradução com uma reflexão linguística que articula a linguagem com as línguas.

Antes de avançarmos com a análise dos processos de apropriação da linguagem na atividade de tradução, que constam da seção 4 , retomaremos algumas polêmicas, nas seções 1,2 e 3 sobre o que se entende por "tradução", por "tradutor" e por "texto" no domínio teórico.

\section{A tradução e a língua como estrutura}

São tributárias do conceito de "modelo" de língua e de tradução aqueles que tratam a língua e a tradução como "sistema" ou como "estrutura". Assumir que uma língua é um sistema implica também assumir que as línguas são objetos relativamente estáticos (invariáveis), tal como é um código. É tributária dessa concepção estática de língua a compreensão de que "a tradução é a substituição do material textual de uma língua pelo material textual equivalente em outra língua" (CATFORD, 1965) e de que o tradutor é mero instrumento de transporte de sentidos estáveis. Traduzir, nesse caso, equivale a reproduzir o conteúdo original em outro código. O conteúdo é inabalável em face da transferência ou da reprodução por sujeitos variados em tempos e espaços 
variados. Desse ponto de vista, a subjetividade, mas não só ela, é entendida como a origem dos desarranjos entre a realidade e o sistema linguístico. Em suma, é "um empecilho para a tradução ideal" (MITTMANN, 2003, p. 22). Acrescente-se que a variação constitutiva da instanciação da língua em situações particulares de discurso é outro empecilho. Na esteira dessas concepções, o eventual desajuste na relação formaconteúdo é tratado como "perda"3 (THEODOR, 1983).

Esse cenário contribui para a formulação de algumas imposições ao tradutor e ao seu trabalho. Por certo, não se admite que: (a) o trabalho de tradução e o sujeito que traduz tenham visibilidade; (b) o tradutor não tenha se apropriado dos valores do textofonte de modo absoluto (presume-se a apropriação); (c) o texto não tenha sido esgotado, isto é, não se admite que ainda existam valores residuais a serem traduzidos.

O transporte de cargas por trens em via férrea é a metáfora que melhor ilustra o funcionamento do "modelo" de língua e de tradução enquanto "sistema". A sequência das palavras de um texto é comparada a uma fileira de vagões de transporte de carga, podendo a carga ser distribuída de maneira irregular entres os diversos vagões. Com efeito, espera-se que alguns vagões tenham mais cargas do que outros ou que uma determinada quantidade de carga possa ser dividida de modo igualitário entre os vários vagões (CATFORD, 1965; NIDA, 1975).

A transposição da ilustração para o domínio linguístico produz a seguinte configuração: algumas palavras expressam vários sentidos, enquanto outras só o fazem se se juntarem a outras palavras. Desse ponto de vista, interessa que os vagões tenham alcançado seu destino (presume-se esse fim). Não interessam a disposição dos vagões ou o modo como a carga esteve distribuída nos vagões (presume-se o desprezo ao processo). Transportada para o domínio da tradução, a ilustração produz a seguinte compreensão: importa que "os componentes significativos do original alcancem a língua-alvo, de tal forma que possam ser usados pelos receptores" (NIDA, 1975, apud ARROJO, 2007, p. 12).

Com os avanços dos sistemas computacionais, ainda na década de 50 do século passado, logo se acreditou - agora sabemos ter sido ingenuidade - na possibilidade de que a máquina substituiria o homem na atividade de traduzir. Esse ideal encontrou naquela ilustração do parágrafo anterior os meios de sua execução. À máquina caberia não só simular a distribuição de significado entre as palavras de uma língua, mas também simular a transposição dos significados das palavras de uma língua para as palavras de outra língua. Por fim, o raciocínio de que traduzir equivale a distribuir significado entre palavras, tal como se distribui carga entre vagões, entusiasmou tanto quanto frustrou inúmeros pesquisadores. Com o avanço das pesquisas, os experimentos voltados ao processamento de textos pela máquina logo mostraram seus limites, quer do ponto de vista técnico-científico quer do ponto de vista estilístico e artístico. Passado meio século, a tradução assistida por máquina ainda é acalentada por muitos pesquisadores.

Até hoje, no entanto, não há disponível no mercado algum programa que seja realmente eficiente, que consiga traduzir um texto do inglês para o português, por exemplo, de maneira tão exata quanto um tradutor humano conseguiria. Isso se deve à complexidade e riqueza das línguas humanas, que relutam em se entregar à formalização do computador (OTHERO, 2006, p. 349).

\footnotetext{
${ }^{3}$ É questionável que se faça a associação da produção das formas das línguas àquela dos bens de consumo. No entanto, não é impossível que se faça tal associação, e é isso o que está sob cotejo aqui.
} 
Se, por um lado, o ideal ilustrado pela metáfora da distribuição de carga ou de significado, respectivamente, em vagões de trens e em palavras, foi - ainda que ingenuamente - perseguido por alguns, por outro lado, também foi questionado por outros. Esses, mais do que aqueles, anteviram os limites do empreendimento que é traduzir.

O conceito de "tradutor fiel", representado, por exemplo, pelo personagem Pierre Menard, do conto Pierre Menard, autor de Quixote, do escritor argentino Jorge Luiz Borges, harmoniza - mas não se confunde - com a concepção de "modelo" de língua ou de sistema linguístico estruturado. O conceito de "tradutor fiel" é anterior ao conceito de sistema linguístico e não se confunde com o conceito de tradutor cuja função é transferir conteúdos de um sistema linguístico a outro. Subjacente à superfície desses conceitos - e nisso se aproximam -, tem-se por fundamento que se passa de um texto a outro sem interferência no conteúdo ou que o conteúdo é independente das formas que dele dizem.

Desse ponto de vista, o conteúdo tem a precedência sobre a expressão ou porque se entende que o conteúdo reflete uma parcela da realidade que se encontra estabilizada ou porque o contrato social assim o assegura. A expressão termina por se reduzir a veículo dos valores de cada cultura. Enquanto objeto cultural, a expressão reproduz aquilo que em cada cultura se quer estável e, portanto, previsível. Não por acaso se tem a impressão de que as línguas reiteram sempre os mesmos valores, as mesmas relações entre forma e conteúdo de outrora. Essa relação se apresenta de tal modo adequada aos sujeitos, que deixa de ser percebida como o resultado de uma prática.

\section{Tradução e o conceito de acontecimento histórico}

Não só em recusa, mas também em oposição ao conceito de "modelo", operatório não só para a ciência moderna, mas também para a linguística moderna e para a teoria da tradução, há um outro conjunto de pesquisadores cujo trabalho se fundamenta sobre o conceito de acontecimento.

Com efeito, a língua e a tradução são tomadas por esses pesquisadores como um acontecimento histórico sempre único (OTTONI, 2005; ARROJO, 2007). Como se trata de um evento datado, a sua apreensão, assim como a sua teorização, implica relacionar a língua e o texto com outros domínios, tais como o social e o cultural. Nesse sentido, o que se entende por texto e por tradução implicam a observação da prática de tradução e a prática de linguagem no meio sócio-político e cultural. É, portanto, da observação da prática e da sua articulação com a teorização, isto é, do vaivém entre prática e teoria, e vice-versa, que se espera chegar ao como a língua e a tradução funcionam no acontecimento de linguagem e de texto.

$\mathrm{Na}$ esteira da concepção de "acontecimento", entende-se que "a tradução é uma atividade essencialmente produtora de significados" (ARROJO, 2007, p.76) e que o tradutor é um sujeito ativo do processo gerador de significação em língua, mas não só. Não só o tradutor, mas toda a comunidade de leitores terá papel ativo no processo interpretativo do texto qualquer que seja ele. A determinação do valor do texto fica na dependência da sua aceitação pela comunidade leitora (ARROJO, 2007). Se ela o aceita como a tradução de um outro texto, esse será o seu valor.

Ainda sob esse ponto de vista, Mittmann afirma: "o tradutor tem um papel ativo e responsável sobre a tradução, que é um ato de transformação e de produção" (MITTMANN, 2003, p. 34). Subjacente ao conceito de "acontecimento" há uma concepção de mundo em constante movimento e de temporalidades dispersivas, que ficam entre a sucessão, a reversão e a projeção. Por isso se entende, sobre esse cenário, 
que cada gesto de tradução "exige do tradutor a capacidade de confrontar áreas específicas de duas línguas e duas culturas diferentes" (ARROJO, 2007, p.78). Ademais, entende-se que o efeito do acontecimento sobre reações contrárias ao movimento e à transformação enseja o confronto. "Já que suas (do acontecimento) variáveis são imprevisíveis" (ARROJO, 2007, p.78). Desse ponto de vista, é no acontecimento de linguagem e de tradução que o sujeito se apropria (apodera-se) das forças em confronto e, com efeito, pode tomar posição. O seu efeito é dado por projeções de acontecimentos futuros.

A subjetividade é a força que sustenta o acontecimento. Ela não garante que o tradutor se aproprie em absoluto do texto, mas também não se esgota num único gesto. Se cada acontecimento esboça outros acontecimentos, sempre haverá confronto por vencer e, em se tratando da tradução, sempre haverá valores por traduzir.

Todo acontecimento implica tomada de posição pelo sujeito, assim como disposição para construir representações adequadas à posição visada. Essa posição não implicaria o ajustamento das formas linguísticas que permitem dela dizer?

\section{Tradução e o conceito de paráfrase}

A tradução é compreendida por Culioli como "um caso particular de paráfrase" (CULIOLI, 1976, p. 29) e o tradutor é aquele que controla os processos de derivação de enunciados no processo de tradução (BIASOTTO, 2010). Nesse sentido, "a prática do tradutor traz similitudes com o trabalho metalinguístico realizado pelo linguista em suas análises textuais" (BIASOTTO, 2010, p. 51). Os conceitos de "tradução" e de "tradutor" estão, portanto, relacionados aos conceitos de "paráfrase"4 e de "trabalho metalinguístico"5 nesse domínio.

Teorizar a tradução enquanto paráfrase implica assumir a impossibilidade da identidade semântica absoluta do texto-fonte com o texto-alvo (BIASOTTO, 2010; PRIA, 2014). Com efeito, o dilema construído em torno da identidade semântica absoluta dá lugar a uma teoria dos observáveis fundamentada no trabalho epilinguístico e metalinguístico, tal como estão definidos pelos trabalhos de Culioli (1990, 1999a, 1999b).

Enquanto a atividade epilinguística é entendida como uma atividade metalinguística não consciente (CULIOLI 1999a) "e se verifica na reflexão inconsciente dos sujeitos sobre sua própria atividade de linguagem" (PRIA, 2009, p. 27), a atividade metalinguística é uma atividade consciente que envolve a apropriação dos mecanismos cognitivos que estão subjacentes à atividade epilinguística do sujeito. A "paráfrase refere-se a uma atividade regulada, controlada" (PRIA, 2009, p. 18 - grifo do autor), da qual o tradutor, tanto quanto o aprendiz, terá de se apropriar.

Através das formas de superfície do texto-fonte, entendidas como marcadoras de operações subjacentes, o tradutor tem de acessar e se apropriar da invariante subjacente ao texto-fonte para, então, poder situá-la em relação a uma situação atual através das formas que lhe estão disponíveis enquanto matéria prima à construção do texto-alvo. Ainda que se possa dizer, de um certo ponto de vista, que diferentes sujeitos chegam a uma mesma proposição, a modulação nunca é a mesma (BIASOTTO, 2010). Já se disse que "se alguma identificação [do texto-alvo com o texto-fonte] for alcançada, terá sido o

\footnotetext{
${ }^{4}$ Fuchs (1985) é uma obra de referência para a compreensão do conceito de "paráfrase".

5 Através dessa atividade metalinguística o sujeito busca se apropriar não só dos mecanismos de derivação de enunciados potenciais, mas também dos mecanismos enunciativos que visam à adequação dos enunciados potenciais a situações particulares de enunciação.
} 
resultado da atividade epilinguística dos sujeitos. No caso de tradutores profissionais, terá sido o resultado também da atividade metalinguística desses sujeitos" (PRIA, 2014, p. 115).

Desse ponto de vista, é uma falsa questão se o tradutor interfere ou não no conteúdo, já que "é inevitável a interferência por parte do tradutor" (BIASOTTO, 2010, p. 44). O tradutor tem de acessar as operações constitutivas do enunciado e se apropriar da invariante que lhe é subjacente, para que possa chegar a produzir ou reconhecer representações interpretáveis em situações particulares de diálogo. A "tentativa de compreender o que o outro quis significar" (BIASOTTO, 2010, p. 47) não traz consigo "a garantia de que se vai ter êxito" (BIASOTTO, 2010, p. 47). De princípio não há garantia de que se vai derivar do texto-fonte uma correspondência na língua-alvo que possa ter tomada como equivalente àquela do texto-fonte. É "ilusório", conforme afirma Biasotto (2010, p. 48), acreditar que qualquer sujeito em qualquer tempo e espaço vá chegar ao mesmo resultado, mas os resultados podem ser aproximados. E é isso que se pretende explicitar através do conceito de equivalência parafrástica.

Segundo Pria (2014), estão subjacentes ao conceito de identificação semântica absoluta: primeiro, a idealização do caráter universal do conteúdo independente da expressão e, segundo, a idealização do sujeito e da situação de enunciação em relação ao conteúdo. Por fim, o pesquisador conclui que essas idealizações produzem, dentre outras, uma concepção estereotipada da tradução e do tradutor. Seguindo esse raciocínio Biasotto (2010) afirma que

uma expressão linguística (seja ela lexical, gramatical ou discursiva) não traz em si um conteúdo inerente e muito menos estável [absoluto], mas é de natureza variável, maleável, e se define pela função que adquire nas interações das quais participa, isto é, só adquire valores quando contextualizada, quando em funcionamento (BIASOTTO, 2010, p. 44).

Desse ponto de vista, não é pertinente tratar a relação entre os textos-fonte-ealvo em termos de identidade absoluta, mas sim em termos de realidades aproximadas. Tratar essa relação em termos de semelhança, de proximidade e de equivalência possibilita abranger a maleabilidade e a flexibilidade da linguagem dentro de uma problemática que

é a diversidade de julgamentos que os linguistas e que os vários sujeitos fazem sobre o conteúdo dos textos-origem e dos textos-traduzidos enquanto manifestações textuais em uma língua dada e a possibilidade de que um mesmo conteúdo ou vários conteúdos distintos possam ser configurados de modos distintos em uma mesma língua ou em várias línguas (PRIA, 2014, p. 116).

No entanto, a atividade de tradução também não se encerra em termos de semelhança, de proximidade e de equivalência.

Não se pode falar que um enunciado traduz outro ou que há equivalência simplesmente por se ter o sentimento de que eles dizem aproximadamente a mesma coisa. É preciso mostrar, por manipulações, que se tem um número de operações que fazem com que esses enunciados possam ser considerados equivalentes (BIASOTTO, 2010, p. 51 - grifo nosso).

Para tanto, o sujeito tem de ser apropriar da ambiguidade constitutiva do enunciado e das operações que o estão sustentando numa língua dada, razão pela qual o enunciado passa uma intuição de significação, ou seja, 
quem não souber que dentro de si próprio já existe uma ambiguidade constitutiva e que os significados se deslocam constantemente, não se entenderá, não se autoconhecerá e desse modo, não terá como alcançar o outro-outro igual a si próprio" (REZENDE, 2011, p. 708).

No enunciado, estão equilibradas representações mais individuais (internas) e mais socializadas (externas). Isso não acontece apenas nas relações intralíngua e intraindivíduo, também acontece nas relações interlínguas e interindivíduos. Quando assumimos a tese da indeterminação da linguagem (REZENDE, 2000), as identidades dos sujeitos e dos textos são tomadas como identidades provisórias, como projetos suscetíveis a ajustamentos. $\mathrm{O}$ resultado da atividade (trabalho) cognitiva (mecanismos) dos sujeitos são os contornos que observamos na superfície das línguas. Não há nenhuma identidade inerente, estável e anterior à prática de construção de significação. As línguas e os sujeitos são sistemas em movimento. Ainda que alguma estabilidade possa ser observada, tem de ser tomada como provisória.

Nessa linha enunciativa, mesmo pessoas muito próximas, que falam arranjos léxico-gramaticais semelhantes não se compreendem. Por isso, seja interlínguas seja intralíngua os significados estão sempre sendo (re)construídos na incessante busca interior de cada sujeito a fim de alcançar a compreensão, que começa por ser a compreensão de si próprio. O indivíduo sozinho já enfrenta o problema da compreensão de si próprio. Essa reflexão traz consigo que os sujeitos estão sempre buscando construir estabilidade para que possa haver diálogo, seja para se fazer entender seja para compreender o outro. Por isso, "a linguagem é um processo de tradução intersujeito e intrassujeito" (REZENDE, 2011). Esse trabalho incessante do sujeito também se encontra na atividade de tradução.

Em nossas análises, buscamos: acessar os mecanismos subjacentes que estão sustentando um enunciado da língua inglesa como tal e explicitar, através da construção de representações metalinguísticas, o processo de apropriação da invariante de forma que estaria na origem do texto-alvo em língua portuguesa.

\section{Processos de apropriação na atividade de tradução}

Analisaremos os processos de apropriação do seguinte enunciado:

\section{(1) John varreu bem limpa a casa.}

$\mathrm{Na}$ leitura desse enunciado, observamos a presença de dois termos: bem e limpa. Ambos os termos marcam a busca pela estabilização do enunciado, até o ponto que um dado sujeito considera ser o mais adequado para uma dada situação de enunciação. Consideremos o termo bem como marca de modalidade intersubjetiva. Essa modalidade nos ajuda a observar uma relação que se estabelecem entre os sujeitos (enunciador e coenunciador). Para alguns casos, esse tipo de modalidade é instituído por meio de um valor de vontade. Em outras palavras, bem corrobora para a apreciação subjetiva do modo de ser limpa da representação casa.

Sob um ponto de vista enunciativo, o termo contribui para desfazer a ambiguidade entre o ato e o efeito. Podemos glosar, ou seja, manipular a construção da significação do ato da seguinte maneira: John varre a casa, o que se sabe é que John varre, ou seja, estabiliza-se uma atividade que é realizada por John. Essa atividade realizada por John, que é suficiente para dar existência a um efeito, podemos glosar da 
seguinte forma: John varreu a casa e como ela ficou limpa. Algumas marcas de asserção são suficientes para a estabilização do efeito de como a casa ficou limpa depois de ter sido varrida (a casa) por John. Constrói-se a apreciação subjetiva sobre aquilo que está sendo dito, através de marcas subjetivas de um sujeito enunciador. Cada sujeito, com seu modo particular de experienciar o mundo físico e mental, constrói representações mentais daquilo que é experienciado.

Limpa é uma propriedade de casa (no pré-construto ser casa é ser limpa). No entanto, a atribuição de limpa precisou ser explicitada no enunciado, isto é, uma propriedade primitiva de casa teve de ser novamente predicada de uma ocorrência atual, haja vista o sujeito enunciador não ter encontrado tal propriedade na ocorrência atual em questão. Consideremos o enunciado John varreu bem limpa a casa sob as seguintes glosas: Está bem limpa como tem que ser, Está como tem que estar. A representação caminha na direção da estabilização de um certo modo de ser limpa de a casa de John.

Agora, bem e limpa, juntos, ressaltam ainda mais a inadequação observada pelo enunciador. Não só se observa uma ocorrência atual de casa que tem a propriedade ser limpa em falta, como também essa inadequação é ressaltada pela presença do adjetivo limpa no enunciado. Com efeito, o sujeito enunciador estabiliza o enunciado, sustentando que tenha havido um ato de varrer por alguém que varre alguma coisa bem limpa. A marca bem limpa é que estabiliza a representação em um ponto mais estável, situado pelo enunciador (os enunciados trazem marcas que remetem a esses ajustamentos).

Bem limpa corrobora a validação da modalidade apreciativa do sujeito enunciador e, nesse caso, instaura-se uma estabilidade que diz respeito à experiência desse sujeito com casas. Sendo essa apreciação de natureza qualitativa e, estando ela centrada no sujeito enunciador, deve ser entendida como manifestação, no enunciado, de julgamentos que dizem respeito à satisfação ou insatisfação do enunciador e ao seu modo de ser favorável ou desfavorável à estabilização possível da representação visada.

$\mathrm{O}$ enunciado traz marcas da trajetória de equilibração que se inicia na experiência (memória) do sujeito enunciador (pré-construto) quanto a um certo modo de ser de casas que são conhecidas do sujeito enunciador, isto é, ocorrências para as quais tenha sido atribuída a propriedade ser limpa. A representação passa por instabilidade (um outro modo de ser de casa), quando John encontra a alteridade, ser quase limpa, ser quase suja, ser suja ou ser limpa, e se estabiliza na experiência do sujeito enunciador (enunciado), que formata de um certo modo possível a representação, isto é, ser bem limpa é o modo como se estabiliza uma ocorrência atual de casa no enunciado. $\mathrm{O}$ enunciado traz marcas desse cálculo que foi feito na trajetória do sujeito enunciador em busca da melhor estabilização possível para a representação diante da alteridade. A estabilização John varreu bem limpa a casa é apreendida pelo sujeito enunciador como uma ocorrência de casa que se observou varrida. Com efeito, foi encontrada como se esperava que fosse. Se, por um lado, temos casa varrida como tem que ser, por outro lado, se não fosse pela marca bem limpa, logo não se estaria diante de uma ocorrência que é como tem que ser. Logo, o enunciado traria outras marcas de ajustamentos quanto ao modo de ser da representação.

Para o enunciado em questão, bem limpa é marca de que o sujeito encontrou obstáculos no processo de construção da representação, obstáculos que colocaram resistência à estabilização da representação. Podemos ter contextos anteriores à situação enunciativa que podem ter interferido na estabilização de John varre bem limpa (como ninguém) a casa. Esses obstáculos estão glosados de (2) a (7):

(2) Mas hoje ele estava com preguiça; 
(3) Estava muito cansado;

(4) Ele está doente;

(5) Porque está triste;

(6) Está com a casa cheia de visitas;

(7) Ele não quer fazer isso, porque quer fazer outra coisa.

Note-se que há um esforço do sujeito enunciador, que antecipa possíveis questionamentos do interlocutor acerca do modo de ser limpa de a casa de John. Bem limpa aparece no enunciado como resultado dessa avaliação. Se voltarmos ao enunciado (7) Ele não quer fazer isso, porque quer fazer outra coisa, podemos ter, ainda, que Ele não quer fazer isso e nem outra coisa, Ele não quer fazer nada. No entanto, mesmo não querendo fazer isso e nem outra coisa, ele ainda o fez.

Deve haver contextos anteriores ao da enunciação para os quais há um modo de ser limpa que ainda não é o modo de ser limpa mais adequado para o contexto atual. Desse modo, o sujeito manuseia, o que esperamos ter conseguido simular satisfatoriamente em nossas análises, o enunciado a ponto de se manifestar no enunciado as marcas dos ajustamentos que resultam do trabalho que lhe é subjacente. É no movimento entre o possível e o adequado a uma dada situação enunciativa que a significação se constrói. Concordamos com a afirmação de que "é essa dinâmica entre o externo (contexto) e o interno da língua (a articulação entre os termos) que gera sentidos mais estáveis" (CUMPRI, 2013, p. 193).

Bem limpa aparece no enunciado em razão de ajustamentos que lhe são subjacentes. A ocorrência atual de casa ainda não é observada como se espera para o sujeito enunciador. De outro modo, se as propriedades capazes de estabilizar a representação já estivessem dadas, não seria preciso todo esse trabalho de manuseio e de ajustamentos.

\section{Considerações Finais}

Observamos, em 1, 2 e 3, que a compreensão do que se entende por "tradução", "tradutor" e por "texto" é sempre tributária daquilo que se entende por "língua" e por "linguagem". Tendo assumido, em 4, a tese de que o objetivo da linguística deva ser a articulação das línguas e da linguagem (CULIOLI, 1990), construímos um sistema de construção metalinguística que simula os processos de apropriação da linguagem na prática de construção de significação. Nessa prática, identificamos a atividade de tradução com a atividade de linguagem definida como "atividade de representação, referenciação e regulação acessível somente através de sequências textuais" (CULIOLI, 1990, p. 14, 179) e, em razão disso, teorizados as sequências textuais das línguas, envolvidas no processo de tradução, como vestígios de representações (cognitivas) subjacentes que se constituem na superfície das línguas como marcadores de operações subjacentes da atividade de linguagem. $\mathrm{Na}$ atividade de tradução, o tradutor se constituiu como um parâmetro operatório que se apropria da linguagem e que constrói representações em vários planos no processo de produção e de reconhecimento de enunciados.

\section{REFERÊNCIAS}

ARROJO, R. Oficina de tradução: a teoria na prática. 5. ed. São Paulo: Ática, 2007. 
BIASOTTO, M. A tradução em termos de equivalência: uma perspectiva culioliana. Versão Beta (UFSCar), v. 8, p. 43-58, 2010.

BERTUCCI, R. Construções resultativas infinitivas em português brasileiro. Alfa, São Paulo, v.58, n.3, p.623-644, 2014.

CATFORD, J. C. A linguistic theory of translation. Oxford: Oxford University Press, 1965.

CULIOLI, A. Representation, referencial processes and regulation. In: CULIOLI, A. Pour une linguistique de l'énonciation: opérations et représentations. Paris: Ophrys, 1990. v. 1. p. 177-213.

CUMPRI, M. L. Sentido, referência e valores referenciais na perspectiva enunciativa. Recorte (UninCor), v. 10, p. 1-13, 2013.

FRANCKEL, J.-J., Introdução. In: VOGÜE, S. de; FRANCKEL, J.-J.; PAILLARD, D. Linguagem e enunciação: representação, referenciação e regulação. São Paulo: Contexto, 2011. p. 15-30.

FUCHS, C. A paráfrase linguística - equivalência, sinonímia ou reformulação? Cadernos de Estudos Linguísticos, n.8, p.129-134, 1985.

MITTMANN, S. Notas do tradutor e processo tradutório. Análise e reflexão sob uma perspectiva discursiva. Porto Alegre: UFRGS, 2003.

NIDA, Eugene. Language structure and translation. California, Stanford University Press, 1975.

OTTONI, P. R. Tradução Manifesta - double bind \& acontecimento. Campinas: Editora da UNICAMP, 2005.

OTTONI, P. R. Tradução - a prática da diferença. 2. ed. Campinas: Editora da Unicamp, 2005.

OTHERO, G. de A. Lingüística Computacional: uma breve introdução. Letras de hoje, v. 41, n. 2, p. 341-351, jun., 2006.

PRIA, A. D.; CARVAlHO, G. A. de. A realização do adjetivo atributivo em português e inglês: correspondências lexicais, sintáticas, semânticas e discursivas. UEG em Revista, v. 1, p. 223-231, 2009.

PRIA, A. D. A atividade de tradução e articulação da invariância com a variação. In: PRIA, A. D. et al (Orgs.). Linguagem e línguas: invariância e variação. Campinas: Pontes, 2014. p. 111-120.

REZENDE, L. M. Léxico e gramática: aproximação de problemas linguísticos com educacionais. Tese (Livre docência) - Faculdade de Ciências e Letras da Universidade Estadual Paulista, Araraquara, 2000.

REZENDE, L. M. A indeterminação da linguagem e o conceito de atividade no ensino de língua materna. Estudos Linguísticos, São Paulo, p.707-714, 2011.

THEODOR, E. Tradução: Ofício e Arte. Editora Cultrix. São Paulo,1983.

Recebido em: junho de 2017.

Como citar este trabalho:

Aprovado em: julho de 2017. 
FLORÊNCIO, E. A.; PRIA, A. D. Processos de apropriação da atividade de tradução e o controle da variação nos textos-alvo. Traços de linguagem, v. 1, n. 1, p. 74-83, 2017. 